\title{
From process management towards dynamic capability
}

\author{
Bo Bergman \\ Centre for Healthcare Improvement, Chalmers \\ University of Technology, Gothenburg, Sweden \\ Correspondence: \\ bo.bergman@chalmers.se \\ Tel.: + 46708341 786; Fax.: + 46317723485
}

Received: 27 July 2016; Accepted: 27 July 2016

Key words: Process management - Quality management - Improvement knowledge •

Exploitation and exploration - Dynamic capability.

Healthcare organizations are facing a large number of challenges: more demanding customers, an aging population, new possibilities for cure and care that require new treatment regimens - sometimes making curing and caring much better, simpler and cheaper but sometimes driving costs. On a global scale, as well as within nations, there are wide variations in quality, safety and equity, and in many healthcare systems costs are increasing. The current digitalization and increased awareness of healthcare as a service activity with the emphasis on co-production is challenging for most healthcare systems. In addition, some countries may have specific problems due to, for example, prior histories of war and migration $(1,2)$. In short, there is a need for a systematic approach towards healthcare improvements.

These challenges have to be met, not only in, for example, primary and secondary care institutions, but also in the education of young, up and coming healthcare professionals. To support them in their prepara- tion for a future working life in an increasingly changing work environment, there is a need for improvements and renewal of educational systems. As emphasised by Batalden and Davidoff (3): We need quality improvement defined as "the combined and unceasing efforts of everyone-healthcare professionals, patients and their families, researchers, payers, planners and educators-to make the changes that will lead to better patient outcomes (health), better system performance (care) and better professional development (learning)." Support from educational institutions is crucial.

The challenges for the education system are accentuated by the new possibilities created by digitalized educational materials, and internet availability that creates new challenges and opportunities difficult to foresee. MOOCs (Massive Open Online Courses) and flipped classrooms are just two new possibilities that will probably change education a great deal. Problem based learning, that has been with us for some time, might be powerfully revived with increased possibilities for simulation of realistic situations and "gamification". Attention has to be re-directed from teaching towards learning - how do we create (or rather sustain) a habit of learning in our young ones, to be sustained throughout their life-long learning.

To improve efficiency, process management (4) has been suggested (see also for example (5)). By critically investigating and mapping how activities are performed in or- 
der to achieve the desired results, it is possible to find possibilities for improvement, i.e. unnecessary activities, inadequate activities and activities that are missing. An ambitious effort to this end is described in (4). The process approach is seen as an important principle of quality management. However, the quality management approach requires a concerted application of a set of interacting principles, of which the process approach is just one. Other principles are: customer focus, fact based decisions, continual improvement, and engagement of people $(6,7)$. Thus, the process approach is not enough. In (4) the business processes were mapped and improvements suggested. However, the most important, the most difficult, and the most challenging parts of the improvement process are still to be realised: that of turning the possibilities for improvement into real changes: "...actual improvements based on implementation of the analysis of the weak points depended on the readiness of the school management to enforce these changes..." (4). To overcome resistance to change, it is important not only to convince management but also those affected by the change. As noted above, people involvement is an important principle of quality management. Thus, it is important to involve and commit people from the early stages of an improvement endeavour. For the success of the approach taken in (4), this aspect is crucial.

For successful improvement of healthcare, it is important to gain an understanding of some important areas of knowledge, as first discussed by Batalden and Stoltz (8) based on what Deming (9) called "profound knowledge". One enhanced interpretation of the domains of improvement knowledge is (2): Understanding variations (not only handling and reduction of variations, but also the positive side of variations, as for example experimentation, exploration and evolution); Psychology and social sciences (the importance of understanding intrinsic motivation and positive psychology, people's often irrational behavior, as discussed by David Kahneman (10), and our dependence on social structures); Knowledge theory, i.e. how knowledge is created (for example: learning cycles as originating from pragmatic philosophy manifested in the PDSAcycle); and understanding of systems and their dynamics and complexity. Currently, improvement knowledge, sometimes also under the heading "Improvement science", is strongly emphasised in the healthcare improvement discourse, $(3,2)$ and references cited there. A special section of Journal of Teacher Education 2015, 66:5, is dedicated to improvement science in education.

In a rapidly changing technology environment, it is not always enough to find the incremental types of improvements indicated above - more radical changes are needed. This creates a dilemma - the organization needs to be both good at working with the current processes and their improvement (exploitation) but also good at exploring new possibilities that may create radically different solutions to the way work is performed (exploration). In a thorough survey of research on process management, Brenner and Tuchman (11) came to the conclusion that process management, even if beneficial in some situations, could be a barrier to exploration, i.e. to finding new technological solutions necessary for meeting future challenges.

The ability to handle exploitation of the current work processes and their improvement, and concurrently to explore radically new ways of working is called "dynamic capability", see for example (12). For healthcare to meet the definition of quality improvement, as described above (3), such a dynamic capability will be essential. The work performed in (4) may be considered a very first step on such a journey.

Conflict of interest: The author declares that he has no conflict of interest. 


\section{References}

1. Institute of Medicine. Crossing the Quality Chasm: A New Health System for the 21st Century, Committee on Quality of Health Care in America. Washington DC: National Academic Press; 2002.

2. Bergman B, Hellström A, Gustavsson S, Lifvergren, S. An emerging science of improvement in healthcare. Qual Eng. 2015;27(1):17-34.

3. Batalden PB, Davidoff F. "What is "quality improvement" and how can it transform healthcare?". Qual Saf Health Care. 2007;16(1):2-3.

4. Sapunar D, Grković I, Lukšić D, Marušić M. The business process management software for successful quality management and organization: A case study from the University of Split School of Medicine. Acta Med Acad. 2016;45(1):26-33.

5. Hellström A, Lifvergren S, Quist, J. Process management in healthcare - investigating why it is easier said than done. Journal of Manufacturing Technology. 2010;21:499-511.
6. Bergman B, Klefsjö B. Quality from Customer Needs to Customer Satisfaction. 3rd ed. Lund: Studentlitteratur; 2010.

7. ISO 9000:2015. Quality management systems fundamentals and vocabulary. 4th ed. [published 2015 Sep 15].

8. Batalden PB, Stoltz PK. A framework for the continual improvement of health care: building and applying professional and improvement knowledge to test changes in daily work. Jt Comm J Qual Improv. 1993;19(10):424-47; discussion 448-52.

9. Deming WE. The new economics. 2nd ed. Cambridge, MA: MIT Press; 1994.

10. Kahneman, D. Thinking, Fast and Slow. New York: Farrar, Strauss \& Giroux; 2011.

11. Benner MJ, Tushman ML. Exploitation, exploration, and process management: the productivity dilemma revisited. Academy of Management Review. 2003;28(2):238-56.

12. Benner MJ, Tushman ML. Reflections on the 2013 Decade Award: "Exploitation, Exploration, and Process Management: The Productivity Dilemma Revisited" ten years later. Academy of Management Review. 2015;40(4):497-514. 